\title{
Modulation of Hippocampal Excitability and Seizures by Galanin
}

\author{
Andrey M. Mazarati, ${ }^{1,4}$ John G. Hohmann, ${ }^{6,8}$ Andrea Bacon, ${ }^{5}$ Hantao Liu, ${ }^{1,4}$ Raman Sankar, ${ }^{2,3}$ \\ Robert A. Steiner, ${ }^{6,7,8}$ David Wynick, ${ }^{5}$ and Claude G. Wasterlain ${ }^{1,3,4}$ \\ ${ }^{1}$ Departments of Neurology, ${ }^{2}$ Pediatrics, and ${ }^{3}$ Brain Research Institute, University of California Los Angeles, School of \\ Medicine, Los Angeles, California 90095-1769, ${ }^{4}$ Epilepsy Research Laboratories, Veterans Affairs, Greater Los Angeles \\ Healthcare System, Sepulveda, California 91343-2099, 5Department of Medicine, Bristol University, Bristol, BS2-8HW \\ United Kingdom, and ${ }^{6}$ Neurobiology and Behavior Program and Departments of 7 Obstetrics and Gynecology, and \\ 8Physiology and Biophysics, University of Washington, Seattle, Washington 98195-7290
}

Previous studies have shown that the expression of the neuropeptide galanin in the hippocampus is altered by seizures and that exogenous administration of galanin into the hippocampus attenuates seizure severity. To address the role of endogenous galanin in modulation of hippocampal excitability and its possible role in seizure mechanisms, we studied two types of transgenic mice: mice with a targeted disruption of the galanin gene (GalKO) and mice that overexpress the galanin gene under a dopamine$\beta$-hydroxylase promoter (GalOE). GalKO mice showed increased propensity to develop status epilepticus after perforant path stimulation or systemic kainic acid, as well as greater severity of pentylenetetrazol-induced convulsions. By contrast, GalOE mice had increased resistance to seizure induction in all three models. Physiological tests of hippocampal excitability revealed enhanced perforant path-dentate gyrus long-term potentiation
(LTP) in GalKO and reduced LTP in GalOE. GalKO showed increased duration of afterdischarge (AD) evoked from the dentate gyrus by perforant path simulation, whereas GalOE had increased threshold for AD induction. Depolarization-induced glutamate release from hippocampal slices was greater in GalKO and lower in GalOE, suggesting that alterations of physiological and seizure responses in galanin transgenic animals may be mediated through modulation of glutamate release.

Our data provide further evidence that hippocampal galanin acts as an endogenous anticonvulsant and suggest that genetically induced changes in galanin expression modulate both hippocampal excitability and predisposition to epileptic seizures.

Key words: galanin; transgenic mice; seizures; hippocampus; long-term potentiation; glutamate
The neuropeptide galanin is widely distributed through the brain of various species (Skofitsch and Jacobowitz, 1985, 1986; Melander et al., 1986; Merchenthaler et al., 1993) and is a potent neuroendocrine regulator of hypothalamo-adrenal hormone release, feeding behavior, insulin secretion, and NPY release (Bauer et al., 1986; Bartfai et al., 1993; Merchenthaler et al., 1993; Wynick et al., 1998). The hippocampus contains few galanin-immunoreactive neurons, but receives abundant galaninergic input from the medial septum, locus coeruleus, and hypothalamus (Melander et al., 1986; Lamour et al., 1988; Senut et al., 1989; Cortes et al., 1990; Merchenthaler et al., 1993). The density of galanin-containing fibers is especially high in the dentate gyrus and CA3 (Mazarati et al., 1998a).

Among the effects of galanin in the hippocampus, presynaptic inhibition of release of the excitatory neurotransmitter glutamate from principal cells, mediated through opening of ATP-dependent $\mathrm{K}$ channels, is of special interest (Zini et al., 1993a,b), because it could modulate hippocampal excitability. Indeed, several lines of research suggest a novel role for galanin in seizures. Thus, the seizure-induced depletion of galanin from the rat hippocampus is associated with the development of self-sustaining status epilepticus (SSSE) (Mazarati et al., 1998b); the injection of galanin into

\footnotetext{
Received March 10, 2000; revised June 2, 2000; accepted June 5, 2000.

This work was supported by Grants NS 11315 from National Institutes of Health and by the Research Service of Veteran Health Administration (C.W.), NS01792 from National Institutes of Health (R.S.), RO1-HD27142 and U54-HD12626 from the National Institute of Child Health and Human Development, IBN97201 from the National Science Foundation, the Pediatric Epilepsy Research Center, and the Alzheimer's Disease Research Center (National Institutes of Health/National Institute on Aging Grant AG 05136), and the University of Washington (R.A.S.). We thank Roger Baldwin, Don Shin, Tom Teal, and Dawit Neraio for their expert technical assistance and Dr. Ulo Langel from Stockholm University for a kind gift of M35.

Correspondence should be addressed to Andrey M. Mazarati, Department of Neurology, University of California Los Angeles School of Medicine, Veterans Affairs Greater Los Angeles Healthcare System, 111N1 Epilepsy Research, 16111 Plummer Street, Sepulveda, CA 91343-2099. E-mail: mailto:mazarati@ucla.edu.

Copyright (C) 2000 Society for Neuroscience $0270-6474 / 00 / 206276-06 \$ 15.00 / 0$
}

the hippocampus attenuates seizure activity, whereas galanin antagonists facilitate it (Mazarati et al., 1992, 1998a). However, the functional significance of endogenous galanin in regulating hippocampal excitability and seizures remains poorly understood.

The study of animals with genetically induced alterations in galanin expression could help to elucidate the contribution of galanin in the regulation of hippocampal function and lend insights into the pathophysiology and treatment of epileptic seizures. We examined hippocampal function and seizure susceptibility in two lines of transgenic mice: one with a targeted deletion of the galanin gene (Wynick et al., 1998; Kerr et al., 2000) and another that overexpresses the galanin gene under the control of the dopamine $\beta$-hydroxylase promoter (Hohmann et al., 1997). Previous analysis of galanin-overexpressing mice (GalOE) revealed increased galanin mRNA in piriform and entorhinal cortices, subiculum, and in noradrenergic cell groups in the brainstem (Hohmann et al., 1997). We found significantly higher $(160 \%)$ levels of galanin, as measured by ELISA, in the brainstem and entorhinal cortex of GalOE compared to wild-type (WT) controls (H. Liu, A. Mazarati, and C. Wasterlain, unpublished data). Studies of galanin knock-out mice (GalKO) revealed undetectable levels of galanin in both the cortex and hypothalamus (Wynick et al., 1998). Therefore, these two types of animals provide a convenient tool for studying the physiological and pathological roles of endogenous galanin.

We provide evidence that altered expression of the galanin gene affects both hippocampal excitability and predisposition to seizures, suggesting that endogenous galanin may play an important role as an endogenous anticonvulsant. These findings raise the possibility that genetic deficits in galanin expression may be a contributory factor in certain forms of epilepsy.

\section{MATERIALS AND METHODS}

Animals. GalKO were bred on the pure 129OlaHsd strain for at least 10 generations. Development of GalKO has been described in detail earlier (Wynick et al., 1998; Kerr et al., 2000). In brief, the entire coding region of the galanin gene was deleted. The generation of GalKO was performed 
using the E14 cell line, and the colony has remained in-bred on the 129OlaHsd strain. The GalOE construct was made by linking a $5.8 \mathrm{~kb}$ section of the human dopamine $\beta$-hydroxylase promoter $(\mathrm{hDBH})(\mathrm{Mercer}$ et al., 1991) to a $4.6 \mathrm{~kb}$ section of the mouse galanin gene, containing the entire galanin coding sequence. This construct was ligated into the plasmid pBS271B.3C. The $10.4 \mathrm{~kb}$ targeting vector was liberated and injected into the pronucleus of fertilized mouse eggs (SJL $\times$ C57BL6) with the services of DNX Transgenic (Princeton, NJ). Of a total of 50 mice screened, four founders carried the transgene. Three lines of mice were established, and all mice used in these studies were from line 1923. This line was backcrossed into the C57BL6/J strain for at least six generations, to remove potential strain-dependent allelic variations that might contribute to behavioral and physiological differences. All GalOE mice used in these studies and their WT controls were genotyped by dot hybridization of genomic DNA to confirm the presence of the $\mathrm{hDBH}$ transgene, as previously described (Mercer et al., 1991). Overexpression of the galanin transgene in specific brain regions of the 1923 line was confirmed by in situ hybridization assays, as well as by radioimmunoassay for total brain galanin content (Hohmann et al., 1997).

The experiments were performed with 12 - to 20 -week-old animals. Our experiments always compared transgenic mice with WT controls of similar genetic backgrounds. All experiments were approved by the Animal Research Committee of the Veterans Affairs Greater Los Angeles Health Care System.

Surgery. Mice were anesthetized with ketamine $(60 \mathrm{mg} / \mathrm{kg}) /$ xylazine $(15 \mathrm{mg} / \mathrm{kg})$ and stereotaxically implanted with a bipolar stimulating electrode into the angular bundle of the perforant path $(0.5 \mathrm{~mm}$ anterior and $2.5 \mathrm{~mm}$ lateral to lambda, $1.5-2.0 \mathrm{~mm}$ ventral from the brain surface) and a bipolar recording electrode into the ipsilateral granule cell layer of the dorsal dentate gyrus $(2.0 \mathrm{~mm}$ posterior and $1.0 \mathrm{~mm}$ lateral to bregma, $1.5-2.0 \mathrm{~mm}$ ventral from brain surface). The final position of both electrodes was optimized by finding a population spike with the amplitude of at least $2 \mathrm{mV}$, evoked from the dentate gyrus by a stimulus delivered to the perforant path $(0.1 \mathrm{msec}, 10 \mathrm{~V}$ square wave monophasic stimuli delivered every $10 \mathrm{sec}$ ). This surgery protocol was used in the experiments with SSSE, afterdischarge (AD) properties, long-term potentiation (LTP), and paired-pulse inhibition. All in vivo experiments were performed in freerunning animals after a $7 \mathrm{~d}$ recovery.

Seizure models. SSSE was induced by $5 \mathrm{sec}$ trains $(0.1 \mathrm{msec}, 10 \mathrm{~V}, 33 \mathrm{~Hz}$ square wave monophasic stimuli) delivered to the perforant path every minute, together with continuous $3 \mathrm{~Hz}$ stimulation using the same parameters. Total seizure time (time spent in EEG seizures after the end of the stimulation) and SE duration (time elapsed between end of stimulation and termination of the last EEG seizure) were measured by means of Harmony Software (Stellate Systems, Montreal, Quebec, Canada). Kainic acid (KA) was administered subcutaneously in doses of 20 or $30 \mathrm{mg} / \mathrm{kg}$. The animals were killed $3 \mathrm{~d}$ after KA, and the brains were sectioned and stained with hematoxylin and eosin. Neuronal damage, evident as the appearance of eosinophilic neurons with pyknotic nuclei (Sankar et al., 1997), was assessed by an unbiased investigator in six $20-\mu \mathrm{m}$-thick sections of the hippocampus from each animal. The extent of the damage was described as minimal (occasional eosinophilic shrunken neurons were found), mild ( 1 of 10 neurons was injured), moderate (up to half of the neurons were injured), or severe (more than half of the neurons appeared to be damaged). Pentylenetetrazol (PTZ) was administered intraperitoneally in doses of $20-60 \mathrm{mg} / \mathrm{kg}$. After injection of KA or PTZ, seizures were videotaped for $2 \mathrm{hr}$ and quantified off-line by an unbiased investigator, according to a modified Racine (1972a) scoring system: 0, no motor seizures; 1 , freezing, mouth, or facial movements; 2 , head nodding or isolated twitches; 3 , unilateral/bilateral forelimb clonus; 4, rearing; 5, rearing and falling; and 6 , tonic seizure with hindlimb extension or death.

Intracerebral injections. For intracerebroventricular injections, the animals were chronically implanted bilaterally with guide cannulas into the lateral ventricles. Rat galanin-[1-29] (American Peptide Company, Sunnyvale, CA), a nonselective agonist for the galanin receptor subtypes 1,2 , and 3 (Bartfai et al., 1992), and M35, a mixed galanin receptor agonist/ antagonist, which possesses predominantly antagonistic effects in the dose used (Antoniou et al., 1997), were injected using a Hamilton microsyringe $(0.5 \mathrm{nmol}$ in $1 \mu \mathrm{l}$ over $5 \mathrm{~min})$.

Studies of afterdischarge properties. To test AD threshold and duration, $2 \mathrm{sec}$ trains of $1 \mathrm{msec}$ square wave biphasic stimuli at $60 \mathrm{~Hz}$ were applied to the perforant path, and the EEG response was recorded from the dentate gyrus. Initial current intensity was $50 \mu \mathrm{A}$ with $50 \mu \mathrm{A}$ increments, $3 \mathrm{hr}$ apart (Mazarati and Wasterlain, 1997a).

Glutamate accumulation. To measure glutamate accumulation, hippocampi from mice that were killed were dissected on ice, cut coronally at $475 \mu \mathrm{m}$, and allowed to recover for $3 \mathrm{hr}$ in $20 \mathrm{ml}$ chambers in ACSF. Samples of $200 \mu \mathrm{l}$ were taken every minute for the first 5 min and then at 10, 20, and $30 \mathrm{~min}$. After collecting baseline samples, slices were placed into ACSF containing $60 \mathrm{~mm} \mathrm{KCl}$ to induce depolarization. Samples were then collected at the same time intervals. The protein content was detected by Lowry assay. Glutamate and aspartate were separated as $O$-phtalaldehyde derivatives by HPLC (Baxter et al., 1991). In a separate set of experiments, hippocampal slices from WT controls for $\operatorname{GalKO}(n=3)$ were treated with M35 $(0.5 \mu \mathrm{M}) 10 \mathrm{~min}$ before $60 \mathrm{~mm} \mathrm{KCl}$-induced depolarization. Control slices were treated with $0.9 \%$ saline instead of M35.

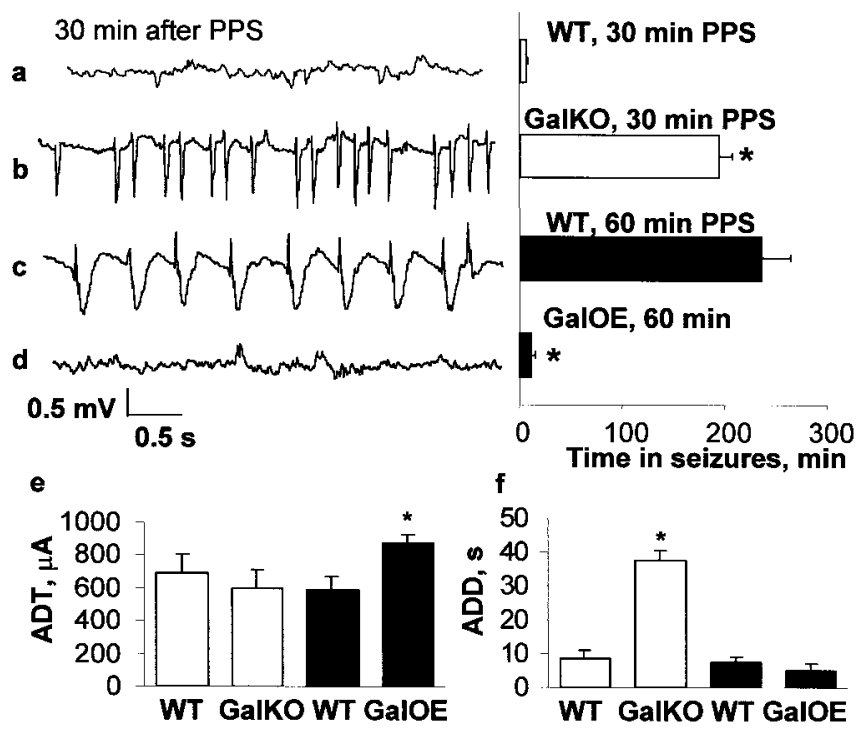

Figure 1. SSSE induced by PPS. Left, EEG in the dentate gyrus $30 \mathrm{~min}$ after the end of PPS. Right, Time in seizures after PPS (mean \pm SEM). PPS for $30 \mathrm{~min}$ was insufficient to induce SSSE in WT $(A)$, but induced SSSE in GalKO $(B)$. PPS for $60 \mathrm{~min}$ induced SSSE in WT controls for GalOE $(C)$, but had no effect in GalOE $(D)$. $E$, Afterdischarge threshold; $F$, afterdischarge duration. For each group, $n=4$. Data are presented as mean \pm SEM. ${ }^{*} p<0.05$ versus respective WT control (Student's $t$ test).

Long-term potentiation in the dentate gyrus in vivo. For test stimulations, the population spike was evoked from the dentate gyrus by stimuli applied to the perforant path $(0.4 \mathrm{msec}$ square wave monophasic stimuli delivered every $10 \mathrm{sec}$ starting at $2 \mathrm{~V}$ with $0.2 \mathrm{~V}$ increments); the intensity of stimulus needed to induce half the maximal population spike was used for tetanic stimulation (three trains of eight pulses for $0.4 \mathrm{msec}$ at $400 \mathrm{~Hz}$ with a $10 \mathrm{sec}$ intertrain interval; Namgung et al., 1995). The population spike (PS) amplitude and EPSP slope were measured as previously described (Shirasaka and Wasterlain, 1994) as an averaged response to 10 consecutive test stimulations delivered at $0.1 \mathrm{~Hz}$, before, and $6 \mathrm{hr}, 2$, and $4 \mathrm{~d}$ after tetanic stimulation. The PS amplitude (in millivolts) was calculated as [(field potential at the beginning of population spike + field potential at the end of population spike) $/ 2$ - (field potential at the peak of population spike)]. The EPSP slope (in millivolts per millisecond) was measured between two fixed points after the EPSP onset and before the PS onset.

Paired-pulse inhibition. Pairs of $10 \mathrm{~V}, 0.1 \mathrm{msec}$ square wave monophasic $0.1 \mathrm{~Hz}$ stimuli were delivered at $40 \mathrm{msec}$ of $400 \mathrm{msec}$ interstimulus intervals (ISI) to study short ISI-dependent and long ISI-dependent inhibition, respectively. Paired pulse inhibition was expressed as the ratio of the average of 10 consecutive second PS (P2) to the average of 10 consecutive first PS (P1) (Shirasaka and Wasterlain, 1994).

Note. In certain cases, the same animals were used for two experiments. Specifically, after the studies of LTP, AD properties, paired-pulse inhibition, or PTZ-induced convulsions, the mice were allowed to recover for 2 weeks, randomized, and used for studies of SSSE, KA-induced seizures or glutamate accumulation.

\section{RESULTS}

We examined the ability of the transgenic mice to develop SSSE, using a protocol similar to that used to study the action of galanin in rats (Mazarati et al., 1998). Intermittent stimulation of the perforant path, the major excitatory input from the entorhinal cortex to the hippocampus (Heinemann et al., 1992), generates seizures that are initially stimulus-bound, but with prolonged stimulation become self-sustaining (Mazarati et al., 1998b). Whereas 30 min of perforant path stimulation (PPS) was not sufficient to induce SSSE in any of WT, all of GalKO developed SSSE with the last seizure observed $345 \pm 45 \mathrm{~min}$ after PPS. In contrast, 60 min PPS induced SSSE in WT controls for GalOE, but only brief seizure activity was observed in GalOE (the last seizure after PPS occurred at $318 \pm 57$ and $25 \pm 5 \mathrm{~min}$, respectively; Fig. $1 a-d$ shows time spent in seizures after PPS).

To determine whether this role of galanin was unique to SSSE, we used a further model of limbic status epilepticus (SE), the systemic administration of KA (Nadler, 1981). In WT controls for GalKO, KA (20 mg/kg, s.c.) induced repetitive stage 1-3 seizures 


\begin{tabular}{|c|c|c|c|}
\hline $\begin{array}{l}\text { Group } \\
\text { (dose of KA) }\end{array}$ & $\begin{array}{l}\text { Number of st. } 5 \\
\text { seizures for } 2 \mathrm{hrs}^{a}\end{array}$ & Mortality & $\begin{array}{l}\text { Neuronal } \\
\text { injury }\end{array}$ \\
\hline $\begin{array}{l}\text { GalKO } \\
(20 \mathrm{mg} / \mathrm{kg})\end{array}$ & $\begin{array}{l}69 \pm 7.3^{*} \\
(45-85)^{b}\end{array}$ & $0 / 6$ & $\begin{array}{l}\text { CA1: }+++ \\
\text { CA3: }++ \\
\text { Hilus: }++\end{array}$ \\
\hline $\begin{array}{l}\text { WT control for } \mathrm{KO} \\
(20 \mathrm{mg} / \mathrm{kg})\end{array}$ & $\begin{array}{l}3.6 \pm 0.7 \\
(2-6)^{b}\end{array}$ & $0 / 6$ & $\begin{array}{l}\text { CA1: }+++ \\
\text { CA3: - } \\
\text { Hilus: - }\end{array}$ \\
\hline $\begin{array}{l}\text { GalOE } \\
(30 \mathrm{mg} / \mathrm{kg})\end{array}$ & $\begin{array}{l}1.4 \pm 1^{*} \\
(0-5)^{b}\end{array}$ & $1 / 6^{*}$ & $\begin{array}{l}\text { CA1: + } \\
\text { CA3: + } \\
\text { Hilus: + }\end{array}$ \\
\hline $\begin{array}{l}\text { WT control for GalOE } \\
(30 \mathrm{mg} / \mathrm{kg})\end{array}$ & $\begin{array}{l}7.2 \pm 1.5 \\
(3-11)^{b}\end{array}$ & $5 / 6$ & $\begin{array}{l}\text { CA1: }(+++)^{c} \\
\text { CA3: }(+++)^{c} \\
\text { Hilus: }(+++)^{c}\end{array}$ \\
\hline
\end{tabular}

- , no injured neurons were found; + , minimal injury;,++ mild injury;

+++ , moderate injury.

${ }^{*} p<0.05$ vs respective WT control (Mann-Whitney $U$ test).

${ }^{a}$ Mean \pm SEM

${ }^{b}$ Numbers in parentheses show minimal and maximal values.

${ }^{c}$ Numbers in parentheses indicate neuronal injury in the only surviving animal in WT controls for GalOE group.

and a few stage 5 seizures. Neuronal injury in the hippocampus was restricted to the $\mathrm{CA} 1$, whereas the $\mathrm{CA} 3$ and dentate hilus were spared (Table 1). In GalKO treated with this same dose of KA, the incidence of stage 5 seizures was 17-fold higher than in WT, and neuronal injury extended to the CA3 and hilus (Table 1). In WT controls for GalOE, KA (30 mg/kg, s.c.) induced severe seizures, which resulted in the death of five of six animals within $30 \mathrm{~min}$. In the single surviving animal, moderate injury was present in the CA1, CA3, and hilus (Table 1). In GalOE this dose of KA induced few stage 5 seizures, which were lethal in only one of six animals, and survivors showed only mild injury to the hippocampus (Table 1). Thus, the ability of animals to establish SE inversely correlated with levels of brain galanin expression in two models of SE in two different lines of mice, suggesting an important role for galanin as an endogenous anticonvulsant.

To extend this conclusion to seizure models beyond SE, we examined the $\mathrm{AD}$ properties in the perforant path-dentate granule cell synapse and the severity of seizures induced by PTZ. Decreased threshold and prolonged duration of $\mathrm{AD}$ reflect higher hippocampal excitability and are often seen in chronic epilepsy (Racine, 1972b; Shirasaka and Wasterlain, 1994; Mazarati and Wasterlain, 1997a). GalKO showed a significantly longer AD duration, and GalOE had a significantly higher AD threshold compared to their respective WT (Fig. $1 E, F$ ). Seizures induced by PTZ (20-60 mg/kg) were more severe in GalKO (Fig. $2 A$ ) and less severe in GalOE (Fig. $2 B$ ) compared to their WT controls.

To confirm that alterations in seizure responsiveness in GalKO and GalOE were mediated by galanin receptors, we examined the effects of galanin receptor ligands on seizure severity. In GalKO, galanin $[0.5 \mathrm{nmol} / \mathrm{side}$, bilaterally into lateral brain ventricles (intracerebroventricularly)] delayed the occurrence of the first seizure and attenuated the severity of PTZ (40 mg/kg)-induced seizures, bringing both indices to the levels observed in WT (Fig. 2C). In GalOE, the administration of M35, a partial galanin receptor agonist, which would be expected to have predominantly antagonist effects at the dose used (0.5 nmol; Antoniou et al., 1997), decreased the latency and increased the severity of PTZ $(50 \mathrm{mg} / \mathrm{kg})$-induced seizures (Fig. 2D). Galanin acts presynaptically to block glutamate release from rat hippocampal slices, possibly by opening ATPsensitive potassium channels (Zini et al., 1993a,b). Because glutamate is a major excitatory neurotransmitter involved in limbic epilepsy (Sloviter and Dempster, 1985), we tested the hypothesis that the observed differences in susceptibility to seizure induction
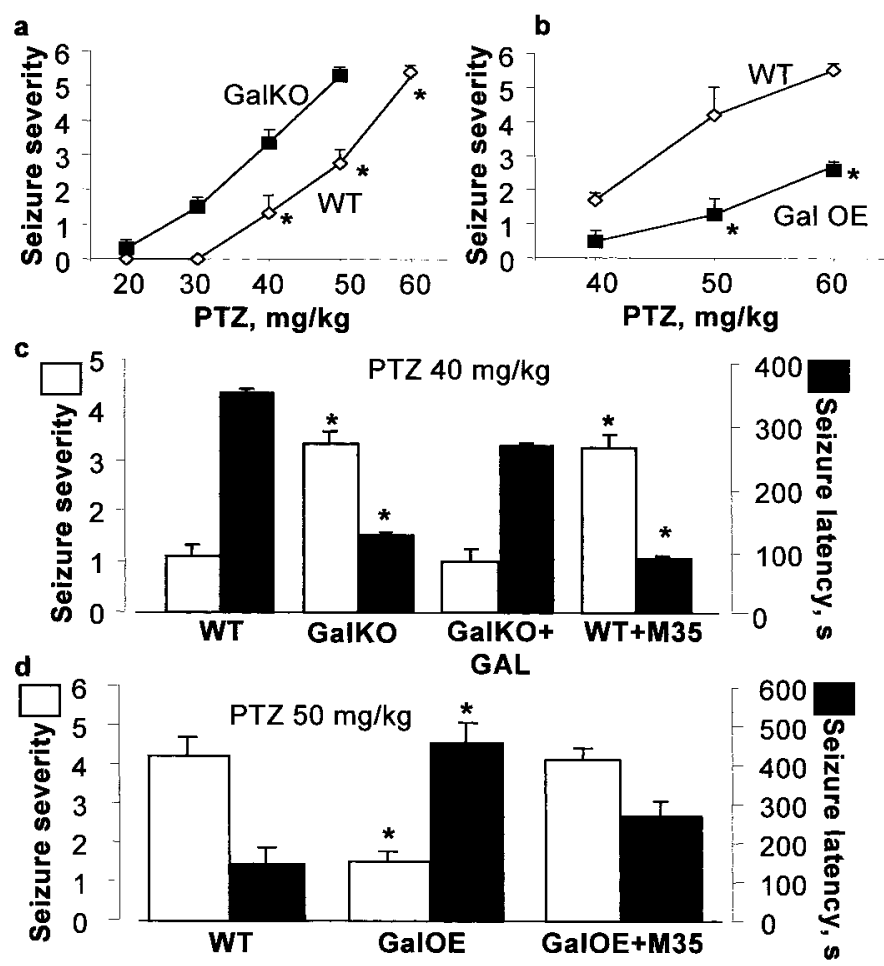

Figure 2. PTZ-induced seizures in transgenic animals. Dose-response to PTZ in GalKO $(A)$ and GalOE $(B)$. $C$, Bilateral intracerebroventricular injection of galanin $(0.5 \mathrm{nmol} / \mathrm{side})$ to GalKO attenuated seizures induced by PTZ $(40 \mathrm{mg} / \mathrm{kg})($ GalKO $+G A L)$, whereas similar administration of M35 (0.5 nmol/side) to WT controls increased seizures $(W T+M 35)$. $D$, GalOE responded with more severe PTZ-induced seizures $(50 \mathrm{mg} / \mathrm{kg})$ when injected bilaterally intracerebroventricularly with $\mathrm{M} 35(0.5 \mathrm{nmol} / \mathrm{side}$; GalOE $+M 35)$. For each group, $n=6$. Data are presented as mean \pm SEM. ${ }^{*} p<0.05$ versus respective WT (Mann-Whitney $U$ test for seizure score and Student's $t$ test for seizure latency).

between GalKO and GalOE are attributable to a differential regulation of glutamate release from the hippocampus in the two mutant strains. There was no difference in basal accumulation of glutamate in the bathing medium among the groups of transgenic and WT animals (Fig. 3A,B). After $\mathrm{KCl}(60 \mathrm{~mm})$-induced depolarization, hippocampal slices from GalKO released significantly more glutamate than slices from WT (Fig. $3 A$ ), whereas slices from GalOE showed no response to the same depolarization challenge (Fig. 3B). In hippocampal slices from WT controls for GalKO, galanin receptor antagonist M35 $(0.5 \mu \mathrm{M})$, did not affect basal glutamate release, but under conditions of $\mathrm{KCl}$-induced depolarization the peptide induced $30 \%$ higher increase of glutamate release than in sham-treated slices $(p<0.05)$.

To further elucidate the mechanisms that contribute to altered seizure responses in the transgenic animals, we examined LTP in the perforant path-dentate gyrus pathway that involved the same morphological substrate as the one used to induce SSSE. Under basal conditions, no differences in both PS amplitude and EPSP slope were observed between WT (Fig. 4A,B) and transgenic animals [half-maximal PS (in millivolts)/EPSP slope (millivolts per millisecond) were $1.6 \pm 0.3 / 0.38 \pm 0.02$ in GalKO, and $1.6 \pm$ $0.2 / 0.37 \pm 0.01$ in GalOE]. In both lines of WT, tetanic stimulation applied to the perforant path induced a 1.6-fold increase in PS amplitude and a 1.7-fold increase in the EPSP slope (Fig. 4A,B), which persisted at $2 \mathrm{~d}$ after LTP induction. In GalKO, the increase in both PS amplitude and the EPSP slope was significantly greater than in WT (2.4- and 2.2-fold respectively), and the latter was still present $4 \mathrm{~d}$ after tetanic stimulation (Fig. $4 C, D$ ). In addition, test stimulations applied after tetanus induced multiple PS, which were never observed in WT (Fig. 4E). Multiple PS reflect granule cell hyperexcitability and are often observed in chronic epilepsy (Sloviter, 1991, 1992; Shirasaka and Wasterlain, 1994). In GalOE, the 

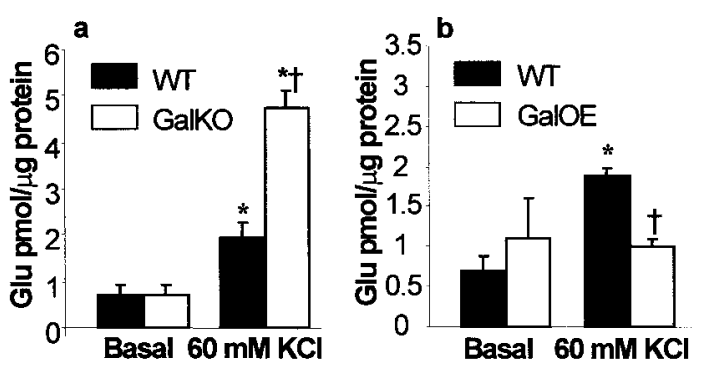

Figure 3. Glutamate accumulation from hippocampal slices of transgenic mice. Samples were taken $5 \mathrm{~min}$ after bath application. Basal glutamate accumulation did not vary significantly among the groups. $A$, During $\mathrm{KCl}$ induced depolarization, hippocampal slices from GalKO $(n=4)$ showed a significantly greater glutamate accumulation than WT $(n=4)$. B, No significant increase of glutamate accumulation was observed in GalOE (for both GalOE and WT; $n=5$ ). Data are presented as mean \pm SEM. * $p<$ 0.05 versus basal release (paired $t$ test); $\uparrow p<0.05$ versus WT (Student's $t$ test). M35 $(0.5 \mu \mathrm{M})$ did not affect basal glutamate accumulation from hippocampal slices of WT controls for GalKO $(n=3)$ but resulted in $30 \%$ larger increase of glutamate accumulation under conditions of $60 \mathrm{mM} \mathrm{KCl}$, compared to sham-treated controls $(p<0.05)$ (data not shown).

initial increase in PS amplitude and the EPSP slope (6 hr after tetanic stimulation) were similar to those in WT; however both parameters had returned to baseline by $2 \mathrm{~d}$ after LTP induction (Fig. 4C,D). Therefore, GalKO showed increased LTP initiation and maintenance compared to WT, whereas GalOE displayed a more rapid LTP decay. a
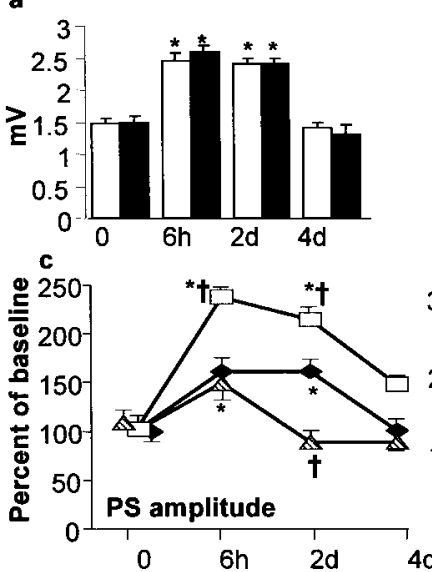

b

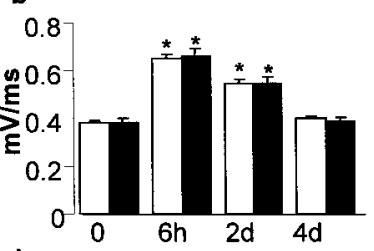

d

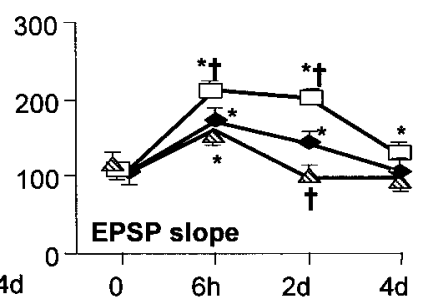

e

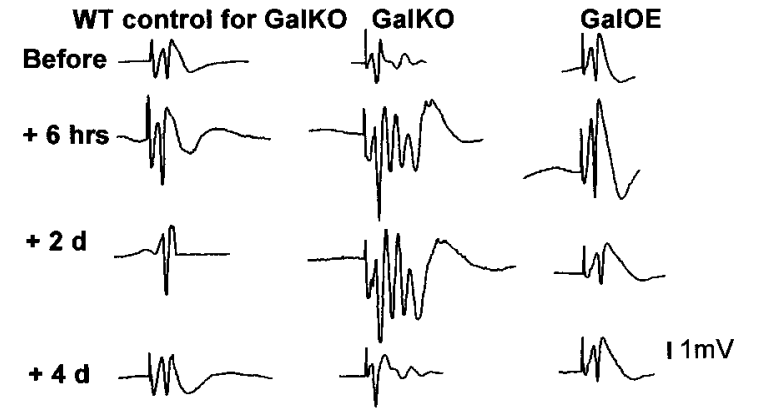

Figure 4. Long-term potentiation in the dentate gyrus of transgenic mice in vivo. Half-maximal population spike $(P S)$ amplitude $(A)$ and EPSP slope $(B)$ after tetanic stimulation of perforant path in WT controls for GalKO (open bars) and WT controls for GalOE (black bars) (mean \pm SEM). No significant differences were observed between the two groups. Halfmaximal PS amplitude $(C)$ and EPSP slope $(D)$ in GalKO (open squares) and GalOE (dashed triangles) compared to WT controls (black diamonds). Data from the two WT groups were pooled, because they were not significantly different from one another. For each group, $n=4$. ${ }^{*} p<0.05$ versus 0 (before tetanus, repeated measures ANOVA \pm Neuman-Keuls test), $\dagger p<0.05$ versus WT (Student's $t$ test). E, Sample responses to test stimulations. Note the appearance of multiple PSs in GalKO after tetanus.

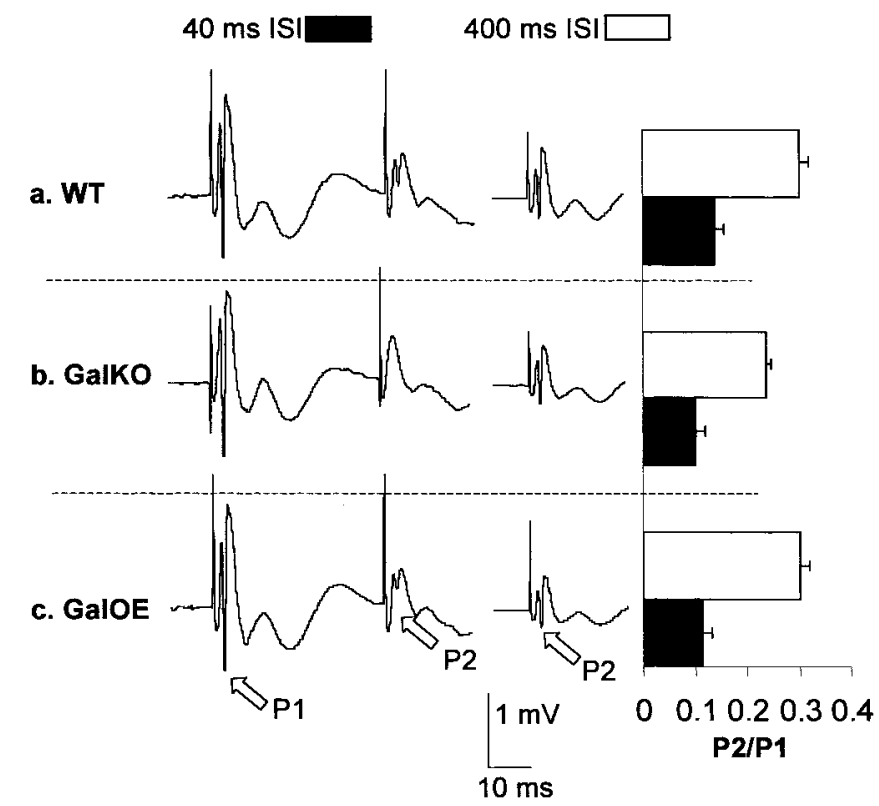

Figure 5. Paired pulse inhibition in the dentate gyrus of transgenic mice in vivo. Left, Sample paired pulse tracings taken from individual animals at 40 and 400 msec ISI. Arrows indicate first (P1) and second (P2) PS (for 400 msec ISI the first PS is omitted because it is the same at $40 \mathrm{msec}$ ISI). Right, The ratio of $\mathrm{P} 2$ to $\mathrm{P} 1$ in the groups show no differences among transgenic and WT animals (black bars, $40 \mathrm{msec}$; open bars, $400 \mathrm{msec}$ ISI). The data from WT controls for GalKO and GalOE are pooled because there were no statistically significant differences between the two groups $(p>0.05$; one-way ANOVA). Data are presented as mean \pm SEM.

Finally, neither short ISI-dependent inhibition (GABA-A) nor long ISI-dependent inhibition differed among WT, KO, and OE animals (Fig. 5), suggesting that dentate circuits of feedback inhibition (Sloviter, 1991, 1992; Shirasaka and Wasterlain, 1994) were functional.

\section{DISCUSSION}

Our results suggest that galanin is a major endogenous modulator of excitability in the mouse hippocampus under a broad variety of physiological and pathological circumstances.

Previous studies in rats showed that the perforant path-dentate gyrus pathway might be critical for the evolvement of SSSE (Vicedomini and Nadler, 1987; Mazarati et al., 1998b). In our experiments we focused primarily on the properties of the perforant path-dentate granule cell synapse to address the importance of endogenous galanin in regulating hippocampal excitability under normal and pathological conditions. Indeed, strong differences were observed between GalKO and GalOE in their ability to develop SSSE, which inversely correlated with the level of galanin expression. Further studies of perforant path-dentate gyrus pathway properties in transgenic animals, revealed different responses under conditions of nonseizure stimulation as well. Increased AD duration in GalKO and increased AD threshold in GalOE suggest that mice lacking galanin have higher excitability of perforant path-dentate gyrus projection, whereas mice overexpressing galanin are more resistant to such stimulation. These data are in accordance with our recent observations that GalKO showed accelerated perforant path kindling compared to their WT controls (A. Mazarati and C. Wasterlain, unpublished data). Furthermore, our studies showing enhanced ability of GalKO to maintain LTP and faster LTP decay in GalOE provide additional confirmation for galanin modulation of hippocampal excitability. It should be mentioned that LTP is enhanced soon after SSSE in rats (Mazarati and Wasterlain, 1997a; Wasterlain et al., 1998) and that the agents that block NMDA-dependent LTP also block SSSE (Mazarati et al., 1999). Therefore, galanin-modulated synaptic potentiation may underlie the observed differences in the ability to develop SSSE in 
transgenic animals. Previous studies showing that exogenously administered galanin inhibits LTP in the CA1 of hippocampal slices from guinea pigs (Sakurai et al., 1996) support this conclusion.

Hence, our experiments suggest that endogenous galanin modulates the physiological properties of the perforant path-dentate granule complex, which commands the gate of entry into the hippocampal trisynaptic excitatory loop and regulates hippocampal excitability under both normal and pathological conditions.

To determine whether the differences between galanin transgenic animals were applicable to other types of seizures, we studied the ability of the animals to develop status epilepticus after injection of KA and under conditions of acute PTZ-induced convulsions. The behavioral pattern of KA-induced limbic seizures in GalKO and GalOE was compatible with the one during SSSE. Milder character of neuronal hippocampal injury in GalOE and greater severity of injury in GalKO confirm the differences in the impact of KA-induced seizures on the hippocampus.

SSSE is dependent on the potentiation of excitatory glutamatergic synapses (Mazarati and Wasterlain, 1997b; Rice and DeLorenzo, 1998; Wasterlain et al., 1998, 1999). To outline the possible biochemical substrate underlying the differences in hippocampal physiology between GalKO and GalOE, we examined glutamate release from hippocampal slices of two types of animals. We found enhanced release of glutamate after depolarization in hippocampi from the GalKO and the reduced release in the slices from GalOE compared to the appropriate WT, suggesting that galanin presynaptically inhibits glutamate release. These observations are compatible with the data showing attenuation of glutamate release from rat hippocampal slices, possibly through opening of ATP-dependent potassium channels (Zini et al., 1993a,b).

In contrast to SSSE, or KA-induced seizures, PTZ seizures originate from the brainstem and medial thalamic nuclei (Miller and Ferrendelli, 1988), where indeed galanin neurons are abundant (Merchenthaler et al., 1993). PTZ-induced convulsions may represent either of two models of epilepsy depending on the dose used: low doses of PTZ (20-40 mg/kg) induce clonic convulsions, a model of petit mal seizures, whereas higher doses of PTZ induce generalized tonic-clonic convulsions, a model of major motor seizures (Woodburry, 1972). The leftward shift of the PTZ-seizure dose-response curve in GalKO and its rightward shift in GalOE compared to respective WT found in our studies extends the anticonvulsant action of endogenous galanin to those two forms of epilepsy. The results of the experiments involving PTZ also suggest that the source of hippocampal modulation by galanin may be extrahippocampal. Indeed, the abundant galanin-immunoreactive fibers seen throughout the hippocampus are the axons of neurons located in medial septum, locus coeruleus, and hypothalamus (Melander et al., 1986), and expression of pre-progalanin mRNA is low in all cell groups of the hippocampus (Melander et al., 1986; Cortes et al., 1990; Merchenthaler et al., 1993).

The experiments with intracerebral injections of galanin receptor ligands suggest that the observed differences between GalKO and GalOE are mediated by galanin receptors. Intracerebroventricular injection of galanin in the GalKO and of M35 in the GalOE brought their seizure responses back toward the WT range. Similarly, in hippocampal slices from WT animals, blocking of galanin receptors by $\mathrm{M} 35$ increased $\mathrm{KCl}$-induced glutamate release, mimicking the differences observed between WT and GalKO animals. M35-induced increase of glutamate release was not as high as that difference between WT and GalKO, which may be attributable to either an incomplete blockade of galanin receptors or to a preferential blockade of one of the subtypes of galanin receptors (e.g., GalR1), leaving other subtype or subtypes (GalR2, GalR3) available for galanin action. On the other hand, in GalKO animals, none of galanin receptor subtypes are functional because of the absence of the endogenous ligand.

Interestingly, neither basal release of glutamate from hippocampal slices, nor $\mathrm{GABA}_{\mathrm{A}}$-mediated recurrent inhibition, as reflected by paired pulse inhibition in the dentate gyrus (Shirasaka and Wasterlain, 1994), were altered in galanin transgenic animals. Fur- thermore, although GalKO mice had a lower seizure threshold, they never developed spontaneous seizures. This finding suggests that galanin has little influence on the hippocampus under resting conditions and shows its modulatory effect only as a response to repetitive or seizure-like stimulation. This conclusion is supported by present and previous (Mazarati et al., 1998a) observations, that M35 alone did not induce seizures in vivo, although it increased the severity of electrically or chemically induced convulsions, and that in vitro M35 did not alter basal glutamate release, but instead increased glutamate release induced by depolarization.

The majority of previous studies of galanin have been performed in the rat. However, the effects of galanin receptor ligands on seizures observed in our experiments along with the pattern of altered responses in galanin transgenic animals, suggest that basic properties of galanin in mice are comparable with those in rats (as well as guinea pigs; Sakurai et al., 1996). Thus, galanin transgenic mice provide a useful tool for studies of galanin physiology.

Several neuropeptides have been implicated in modulation of hippocampal function and seizure activity (Marksteiner et al., 1990; Drake et al., 1994; Harrison et al., 1995; Liu et al., 1999b; Mazarati et al., 1999). The advances in molecular biology that have allowed construction of transgenic animals have introduced a novel approach to analyze the role of these peptides in seizures. Recent findings using transgenic mice with NPY (Baraban et al., 1997) or substance P (Liu et al., 1999a) mutations revealed a critical role of these two peptides in seizures. The present report shows an important role of galanin as a putative "endogenous anticonvulsant." Taken together, these findings suggest that although there is no "ultimate" proepileptic or antiepileptic peptide, very fine abnormalities in peptide-modulated tuning of hippocampal functioning as a result of inherited or acquired defects may strongly affect predisposition of the brain to epilepsy. As a result, neuropeptide receptors may become a target for the development of new antiepileptic drugs.

In conclusion, galanin may counteract excess excitation in response to physiological or pathological stimuli and may offer a mechanism by which deep brain nuclei modulate hippocampal function and excitability. An intriguing speculation is that inherited defects in the expression of this endogenous anticonvulsant may be epileptogenic in animals or humans. As a result, galanin agonists have the potential of making excellent anticonvulsants, because they may be able to inhibit a broad variety of seizures in the pathologically activated hippocampus while relatively sparing normal brain function.

\section{REFERENCES}

Antoniou K, Kehr J, Snitt K, Ogren SO (1997) Differential effects of the neuropeptide galanin on striatal acetylcholine release in anaesthetized and awake rats. Br J Pharmacol 121:1180-1186.

Baraban SC, Hollopeter G, Erickson JC, Schwartzkroin PA, Palmiter RD (1997) Knock-out mice reveal a critical antiepileptic role for neuropeptide Y. J Neurosci 17:8927-8936.

Bartfai T, Fisone G, Langel U (1992) Galanin and galanin antagonists: molecular and biochemical perspectives. Trends Pharmacol Sci $13: 312-317$

Bartfai T, Hökfelt T, Langel Ü (1993) Galanin: a neuro-endocrine peptide. Crit Rev Neurobiol 7:229-274.

Bauer FE, Ginsberg L, Venetikou M, MacKay DJ, Burrin JM, Bloom SR (1986) Growth hormone release in man induced by galanin, a new hypothalamic peptide. Lancet 2:192-195.

Baxter CF, Oh CC, Wasterlain CG, Ozaki LK, Baldwin RA (1991) Alterations of GABA metabolism and seizure susceptibility in the substantia nigra of the kindled rat acclimating to changes in osmotic state. Neurochem Res 16:269-278.

Cortes R, Ceccatelli S, Schalling M, Hokfelt T (1990) Differential effects of intracerebroventricular colchicine administration on the expression of mRNAs for neuropeptides and neurotransmitter enzymes, with special emphasis on galanin: an in situ hybridization study. Synapse 6:369-391.

Drake CT, Terman GW, Simmons ML, Milner TA, Kunkel DD, Schwartzkroin PA, Chavkin C (1994) Dynorphin opioids present in dentate granule cells may function as retrograde inhibitory neurotransmitters. J Neurosci 14:3736-3750.

Harrison MB, Shumate MD, Lothman EW (1995) Opioid peptide expression in models of chronic temporal lobe epilepsy. Neuroscience 65:785-795.

Heinemann U, Beck H, Dreier JP, Ficker E, Stabel J, Zhang CL (1992) 
The dentate gyrus as a regulated gate for the propagation of epileptiform activity. In: The dentate gyrus and its role in seizures (Ribak CE, Gall CM, Mody I, eds) pp 273-280. Amsterdam: Elsevier.

Hohmann JG, Cadd GC, Teal TH, Clifton DK, Steiner RA (1997) Transgenic mice that overexpress the galanin gene in brainstem neurons. Soc Neurosci Abstr 23:1878.

Kerr BJ, Cafferty WB, Gupta YK, Bacon A, Wynick D, McMahon SB, Thompson SW (2000) Galanin knockout mice reveal nociceptive deficits following peripheral nerve injury. Eur J Neurosci 12:793-802.

Lamour Y, Senut MC, Dutar P, Bassant MH (1988) Neuropeptides and septo-hippocampal neurons: electrophysiological effects and distributions of immunoreactivity. Peptides 9:1351-1359.

Liu H, Cao Y, Basbaum AI, Mazarati AM, Sankar R, Wasterlain CG (1999a) Resistance to excitotoxin-induced seizures and neuronal death in mice lacking the preprotachykinin A gene. Proc Natl Acad Sci USA 96:12096-12101.

Liu H, Mazarati AM, Katsumori H, Sankar R, Wasterlain CG (1999b) Substance $\mathrm{P}$ is expressed in hippocampal principal neurons during status epilepticus and plays a critical role in the maintenance of status epilepticus. Proc Natl Acad Sci USA 96:5286-5291.

Marksteiner J, Ortler M, Bellmann R, Sperk G (1990) Neuropeptide Y biosynthesis is markedly induced in mossy fibers during temporal lobe epilepsy of the rat. Neurosci Lett 112:143-148.

Mazarati A, Wasterlain C (1997a) Loss of hippocampal inhibition and enhanced LTP after self-sustaining status epilepticus. Epilepsia [Suppl] 38:178.

Mazarati AM, Wasterlain CG (1997b) Selective facilitation of kindled seizures from the amygdala after hippocampal lesions induced by perforant path stimulation. Neurosci Lett 224:165-168.

Mazarati AM, Wasterlain CG (1999) $N$-methyl-D-aspartate receptor antagonists abolish the maintenance phase of self-sustaining status epilepticus in rat. Neurosci Lett 265:187-90.

Mazarati AM, Halaszi E, Telegdy G (1992) Anticonvulsive effects of galanin administered into the central nervous system upon the picrotoxinkindled seizure syndrome in rats. Brain Res 589:164-166.

Mazarati A, Liu H, Soomets U, Sankar R, Shin D, Katsumori H, Langel U, Wasterlain CG (1998a) Galanin modulation of seizures and seizure modulation of hippocampal galanin in animal models of status epilepticus. J Neurosci 18:10070-10077.

Mazarati AM, Wasterlain CG, Sankar R, Shin D (1998b) Self-sustaining status epilepticus after brief electrical stimulation of the perforant path. Brain Res 801:251-253.

Mazarati AM, Liu H, Wasterlain CG (1999) Opioid peptide pharmacology and immunochemistry in an animal model of self-sustaining status epilepticus. Neuroscience 89:167-173.

Melander T, Staines WA, Rokaeus A (1986) Galanin-like immunoreactivity in hippocampal afferents in the rat, with special reference to cholinergic and noradrenergic inputs. Neuroscience 19:223-240.

Mercer EH, Hoyle RP, Kapur RP, Brinster RL, Palmiter RD (1991) The dopamine $\beta$-hydroxylase gene promoter directs expression on E.Coli lacZ to sympathetic and other neurons in adult transgenic mice. Neuron 7:703-716.

Merchenthaler T, Lopez FJ, Negro-Vilar A (1993) Anatomy and Physiology of central galanin-containing pathways. Prog Neurobiol 40:711-769.

Miller JW, Ferrendelli JA (1988) Brain stem and diencephalic structures regulating experimental generalized (pentylenetetrazol) seizures in rodents. In: Anatomy of epileptogenesis (Meldrum BS, Ferrendelli JA, Wieser HG, eds) pp 57-69. London: John Libbey.

Nadler JV (1981) Minireview. Kainic acid as a tool for the study of temporal lobe epilepsy. Life Sci 29:2031-2042.
Namgung U, Valcourt E, Routtenberg A (1995) Long-term potentiation in vivo in the intact mouse hippocampus. Brain Res 689:85-92.

Racine RJ (1972a) Modification of seizure activity by electrical stimulation: motor seizures. Electroencephalogr Clin Neurophysiol 32:281-294.

Racine RJ (1972b) Modification of seizure activity by electrical stimulation. I. Afterdischarge threshold. Electroencephalogr Clin Neurophysiol 32:269-279.

Rice AC, DeLorenzo RJ (1998) NMDA receptor activation during status epilepticus is required for the development of epilepsy. Brain Res 782:240-247.

Sakurai E, Maeda T, Kaneko S, Akaike A, Satoh M (1996) Galanin inhibits long-term potentiation at Schaffer collateral-CA1 synapses in guinea-pig hippocampal slices. Neurosci Lett 212:21-24.

Sankar R, Shin D, Wasterlain CG (1997) Serum neuron- specific enolase is a marker for neuronal damage following status epilepticus in the rat. Epilepsy Res 28:129-136.

Senut MC, Menetrey D, Lamour Y (1989) Cholinergic and peptidergic projections from the medial septum and the nucleus of the diagonal band of Broca to dorsal hippocampus, cingulate cortex and olfactory bulb: a combined wheatgerm agglutinin-apohorseradish peroxidase-gold immunohistochemical study. Neuroscience 30:385-403.

Shirasaka Y, Wasterlain CG (1994) Chronic epileptogenicity following focal status epilepticus. Brain Res 655:33-44.

Skofitsch G, Jacobowitz DM (1985) Immunohistochemical mapping of galanin-like neurons in the rat central nervous system. Peptides 6:509-546.

Skofitsch G, Jacobowitz DM (1986) Quantitative distribution of galaninlike immunoreactivity in the rat central nervous system. Peptides 7:609-613.

Sloviter RS (1991) Permanently altered hippocampal structure, excitability and inhibition after experimental status epilepticus in the rat: the "dormant basket cell" hypothesis and its possible relevance to temporal lobe epilepsy. Hippocampus 1:41-46.

Sloviter RS (1992) Possible functional consequences of synaptic reorganization in the dentate gyrus of kainate-treated rats. Neurosci Lett 137:91-96.

Sloviter RS, Dempster DW (1985) Epileptic brain damage is replicated qualitatively in the rat hippocampus by central injection of glutamate and aspartate but not by GABA and acetylcholine. Brain Res Bull 15:39-60.

Vicedomini JP, Nadler JV (1987) A model of status epilepticus based on electrical stimulation of hippocampal afferent pathways. Exp Neurol 96:681-691.

Wasterlain CG, Mazarati AM, Sankar R, Shirasaka Y, Thompson K (1998) Potentiation of kindling and long-term potentiation by hippocampal lesions. In: Kindling 5. (Corcoran M, Moshe M, eds) pp 501-510. New York: Plenum.

Woodburry DM (1972) Applications to drug evaluations. In: Experimental models of epilepsy (Purpura DP, Penry JK, Tower DB, Walter RB, eds) pp 557-585. New York: Raven.

Wynick D, Small CJ, Bacon A, Holmes FE, Norman M, Ormandy CJ, Kilic E, Kerr NC, Ghatei M, Talamantes F, Bloom SR, Pachnis V (1998) Galanin regulates prolactin release and lactrotroph proliferation. Proc Natl Acad Sci USA 95:12671-12676.

Zini S, Roisin M, Langel U, Bartfai T, Ben-Ari Y (1993a) Galanin reduces release of endogenous excitatory amino acids in the rat hippocampus. Eur J Pharmacol 245:1-7.

Zini S, Roisin MP, Armengaud C, Ben-Ari Y (1993b) Effects of potassium channels moduators on the release of glutamate induced by ischaemic-like conditions in rat hippocampal slices. Neurosci Lett 153: 202-205. 